\title{
Alles ist gesagt
}

\section{Anna Sax}

Lic. oec. publ., MHA, Mitglied der Redaktion

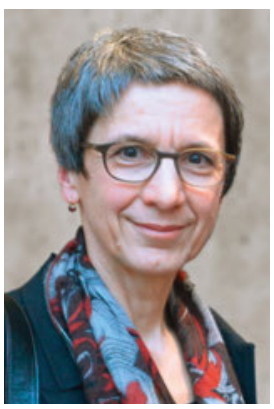

Es ist wieder Krankenkassenwechsel-Saison. Und so äussert sich männiglich, wer oder was verantwortlich sei für das Wachstum der Gesundheitskosten und was dringend zu tun sei, um die Misere zu besiegen. Ich aber verspreche hiermit, dass ich von nun an darauf verzichten werde, Schuldzuweisungen $\mathrm{zu}$ verteilen und mich zu jedem gesundheitspolitischen Fehlentscheid zu äussern. Sie werden sich vielleicht fragen, was mich dazu treibt, meinen Geltungsdrang zu zügeln und mich aus dem bunten Expertinnen- und Expertentreiben zurückzuziehen.

Auslöser für meine neue Zurückhaltung ist der Expertenbericht «Kostendämpfungsmassnahmen zur Entlastung der obligatorischen Krankenpflegeversicherung", den das Departement des Innern EDI Ende Oktober veröffentlichte. Oder vielmehr sind es die Reaktionen darauf. Kaum war der Bericht publiziert, meldeten sich nämlich die Interessenverbände. Wie aus der Pistole geschossen wetterten Ärztinnen, Patienten, Krankenkassen, Spitäler, Apotheken und Pharmaindustrie unisono gegen die drohende «Rationierung» und «Zweiklassenmedizin». «Es wäre die Abkehr vom solidarisch gelebten Gesundheitssystem in der Schweiz", schrieben die Absender der Medienmitteilung, darunter solche, die man bisher vor allem als Fürsprecher von mehr Wettbewerb und Eigenverantwortung kannte. Hauptziel der konzertierten Attacke ist ein im Expertenbericht vorgeschlagenes Globalziel für die Kostenentwicklung, sprich: ein Globalbudget. Die Idee dabei ist, das Kostenwachstum in der obligatorischen Grundversicherung mittels Mengenbegrenzungen schrittweise zu drosseln, so dass am Schluss die Krankenkassenprämien noch etwa im Gleichschritt mit den Löhnen wachsen könnten.

Kaum war der Bericht publiziert, meldeten sich die Interessenverbände.

Ich reibe mir als erstes die Augen angesichts der geballten Empörung des gesundheitspolitischen Establishments. Dann nehme ich mir den Bericht vor: Eine international zusammengesetzte Expertengruppe hat darin insgesamt 38 Massnahmen aufgeführt. Es handelt sich um konkrete Vorschläge, einige sind schon länger im Gespräch, andere sind neu. Sie sind priorisiert, klar umschrieben und begründet, zahlreiche Beispiele aus dem Ausland werden angeführt. Aufgefallen ist mir zum Beispiel der Verzicht auf mengenabhängige Boni und Kickbacks in Spitälern als Bedingung für die Aufnahme auf die kantonalen Spitallisten. Interessant ist auch die Idee, einen "Experimentierartikel» ins KVG aufzunehmen, der es zum Beispiel erlauben würde, neue Vergütungsmodelle auszuprobieren. Weiter greifen die Autorinnen und Autoren mit den Indikationsboards ein Instrument auf, das im Prinzip unbestritten, aber ausser in der Onkologie bisher kaum zum Einsatz gekommen ist, weil wirtschaftliche Interessen tangiert werden.

\section{Wer sich aber darin vertieft, erkennt, dass es ebenso sehr um Transparenz und Qualität geht.}

Sicher, nicht alle 38 Massnahmenvorschläge sind für sich genommen gleichermassen überzeugend. Aber insgesamt handelt es sich um ein sorgfältig geschnürtes Paket. Laut dem Titel des Berichts geht es zwar um Massnahmen zur Kostendämpfung. Wer sich aber darin vertieft, erkennt, dass es ebenso sehr um Transparenz und Qualität geht. Wenn sich nun die wichtigsten Interessenvertreter auf eine zentrale Massnahme einschiessen, dann heisst das im besseren Fall, dass sie noch nicht die Zeit gefunden haben, den ganzen Bericht zu lesen. Im schlechteren Fall muss ich daraus schliessen, dass die Profiteure eines intransparenten, ineffizienten und nach aussen abgekapselten Systems alles versuchen, um ihre Pfründe zu bewahren.

Was es zur Kostenentwicklung im Gesundheitswesen und zu ihren Ursachen zu sagen gibt, ist gesagt. Ich habe vorläufig nichts hinzuzufügen. Es trifft sich deshalb gut, dass meine Zeit als Redaktorin der Schweizerischen Ärztezeitung abläuft und dieses mein letztes «Zu guter Letzt» an dieser Stelle ist. Und so verabschiede ich mich nach zehn Jahren von Ihnen, liebe Leserinnen und Leser, mit einem herzlichen Dankeschön für alle Ihre kritischen, erfrischenden und aufbauenden Kommentare. 